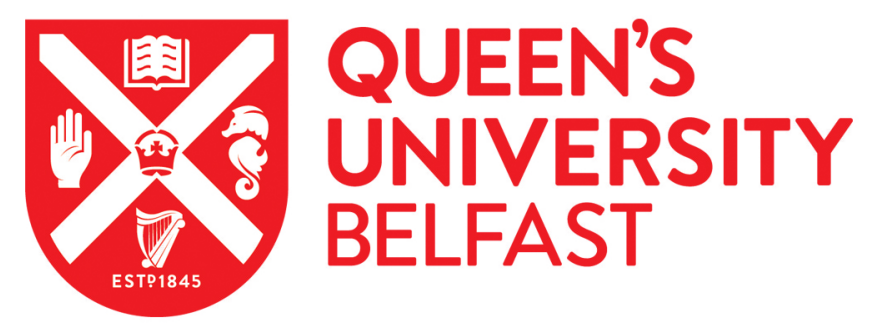

\title{
Changing antiepilepsy drug-prescribing trends in women with epilepsy in the UK and Ireland and the impact on major congenital
} malformations

Kinney, M. O., Morrow, J., Patterson, C. C., Campbell, E., Russell, A., Smithson, H. W., Parsons, L., Morrison, P. J., Bromley, R., Liggan, B., Delanty, N., Irwin, B., Hunt, S. J., \& Craig, J. J. (2018). Changing antiepilepsy drug-prescribing trends in women with epilepsy in the UK and Ireland and the impact on major congenital malformations. Journal of neurology, neurosurgery, and psychiatry. https://doi.org/10.1136/jnnp-2017-317368

Published in:

Journal of neurology, neurosurgery, and psychiatry

Document Version:

Peer reviewed version

Queen's University Belfast - Research Portal:

Link to publication record in Queen's University Belfast Research Portal

Publisher rights

(c) 2018 The Authors. This work is made available online in accordance with the publisher's policies. Please refer to any applicable terms of use of the publisher.

\section{General rights}

Copyright for the publications made accessible via the Queen's University Belfast Research Portal is retained by the author(s) and / or other copyright owners and it is a condition of accessing these publications that users recognise and abide by the legal requirements associated with these rights.

\section{Take down policy}

The Research Portal is Queen's institutional repository that provides access to Queen's research output. Every effort has been made to ensure that content in the Research Portal does not infringe any person's rights, or applicable UK laws. If you discover content in the

Research Portal that you believe breaches copyright or violates any law, please contact openaccess@qub.ac.uk. 
Short report: Changing anti-epilepsy drug prescribing trends in women with epilepsy in the UK and Ireland and the impact on major congenital malformations.

Kinney M.O. ${ }^{1}$, Morrow J' ${ }^{1}$, Patterson C.C. ${ }^{2}$, Campbell E ${ }^{1}$, Russell $\mathrm{A}^{3}$, Smithson $\mathrm{WH}^{4}$, Parsons $\mathrm{L}^{5}$, Morrison PJ6, Bromley R $\mathrm{R}^{7}$ Liggan $\mathrm{B}^{8}$, Delanty $\mathrm{N}^{8}$, Irwin $\mathrm{B}^{1}$, Hunt SJ1 , Craig J.J. ${ }^{1}$.

1- Neurology Department, Belfast Health and Social Care Trust, Royal Victoria Hospital, Grosvenor Road, Belfast, Northern Ireland.

2- Centre for Public Health, Queen's University Belfast, Institute of Clinical Sciences Block B, Grosvenor Road, Belfast, BT12 6BJ, Northern Ireland.

3- Department of Clinical Neurophysiology, Institute of Neurological Sciences, Southern General Hospital, 1345 Govan Road, Glasgow, Scotland.

4- Department of General Practice, University College Cork Ireland, Western Gateway Building, Western Road, Cork, Ireland.

5- Neurology Department, Luton \& Dunstable Hospitals NHS Trust, Lewsley Road, Luton, England.

6- Department of Medical Genetics, Belfast Health and Social Care Trust, Belfast City Hospital, Lisburn Road, Belfast, Northern Ireland.

7- Royal Manchester Children's Hospital, Central Manchester University Foundation NHS Trust, Manchester, England and The Institute of Human Development, The University of Manchester, England.

8- Department of Neurology, Beaumont Hospital, Dublin, Ireland.

Address for correspondence;

Dr John Craig,

Department of Neurology,

Belfast Health and Social Care Trust,

Grosvenor Road, 
Belfast,

BT12 6BA.

United Kingdom.

Tel No; +442890634590

Fax No; +442890235238

Email: john.craig@belfasttrust.hscni.net

Title word count- 21

Abstract word count- 302

Manuscript word count-1840

Number of Pages-13

Number of References-15

Search terms: [60] All Epilepsy/ seizures, [61] Antiepileptic drugs. 
Disclosures:

M.O. Kinney has received salary support to conduct a sabbatical of out of programme study from UCB paid in its entirety through the Belfast Health and Social Care Trust.

J Morrow has received unrestricted educational grants from Eisai, Glaxo Smith Kline, Novartis, Sanofi-Aventis, Pfizer and UCB for the running of the UK Epilepsy and Pregnancy Register.

C.C. Patterson reports no disclosures

E. Campbell reports no disclosures

A Russell has received a grant from UCB for funding of a research nurse (2006-9) and received small contributions from UCB, Glaxo Smith Kline, Eisai, Forth Medical, Cyberonics and Optima Medical to cover the costs of the UK Epilepsy Surgery Meeting in Glasgow in 2011.

WH Smithson has been invited to attend advisory board meetings for NAPP and SanofiAventis.

L Parsons has received honoraria for presentations from UCB.

B Irwin has received sponsorship to attend meetings and honoraria for presentations from Eisai, UCB and Sanofi-Aventis.

R. Bromley has received lecture fees from Sanofi Aventis (two occasions), received on one occasion conference travel support from UCB Pharma and a single consultancy fee. She has previously provided expert testimony pertaining to fetal anticonvulsant syndrome.

B Liggan has received honoraria for attending a UCB pharma Irish Nurse Advisory Board meeting. 
N Delanty has received unrestricted educational support from UCB Pharma, Eisai, GSK, Janssen-Cilag, and Pfizer for running of the Irish Epilepsy Pregnancy register.

P Morrison reports no disclosures.

S Hunt has received sponsorship to attend meetings from Eisai, UCB and Glaxo Smith Kline. He has also received honoraria for presentations from Pfizer and UCB.

$\mathrm{J}$ Craig has received grants to undertake research and honoraria for giving lectures from UCB-Pharma, Sanofi-Synthelabo, Glaxo Smith Kline, Janssen-Cilag, Pfizer and Eisai. 


\section{$\underline{\text { Abstract }}$}

Objectives: After 20 years of data collection, pregnancy registers have informed prescribing practice. Various populations show trends for a reduction in valproate prescribing, which is associated with an increased risk of anatomical teratogenesis and neurodevelopmental effects in those exposed in utero. Our aim was to determine if any shifts in prescribing trends have occurred in the UK and Ireland Epilepsy and Pregnancy Register cohort, and to assess if there had been any change in the overall major congenital malformation (MCM) rate over time.

Methods: The UK and Ireland Epilepsy and Pregnancy Register, a prospective, observational, registration and follow up study established in 1996, was used to determine the changes in antiepileptic drugs (AEDs) utilised during pregnancy and the MCM rate between 1996 and 2016. Linear regression analysis was used to assess changes in AED utilisation, and Poisson regression was used for the analysis of trends in the MCM rates.

Results: Outcome data for 9247 pregnancies showed a stable percentage of monotherapy to polytherapy prescribing habits over time. After Bonferroni correction, statistically significant $(P<0.003)$ changes were found in monotherapy prescribing with increases in lamotrigine and levetiracetam and decreases in valproate and carbamazepine use. Between 1996 and 2016 the total MCM appeared to show 2.1\% reduction in MCM rate per year (Incidence risk ratio 0.979 [95\% confidence intervals $0.956-1.002]$ but Poisson regression analysis showed that this was not statistically significant $P=0.08$ ).

Conclusion: Significant changes are seen in the prescribing habits in this cohort over 20 years, but a statistically significant change in the MCM rate was not detected. This work should be replicated on a larger scale to determine if significant changes are occurring in the MCM rate, which would allow a robust economic estimate of the benefits of improvements in prescribing practice and the personal effect of such changes. 


\section{$\underline{\text { Introduction }}$}

For two decades various epilepsy and pregnancy registers have prospectively gathered data on pregnancy outcomes in women with epilepsy (WWE) exposed to antiepileptic drugs (AEDs) (1). The consensus from these various registry studies is that, in order to reduce the risk of major congenital malformation (MCM), WWE should take low dose AEDs in monotherapy and preferably avoid valproate whenever possible $(2,3,4)$. Prescribing trends reported from different regions indicate a change in prescribing practice $(5,6,7,8)$.

In general, trends in prescribing in WWE have shown that valproate and carbamazepine use has declined. In their place lamotrigine and levetiracetam have become the two most commonly prescribed AEDs $(6,7,8)$. These changes could be predicted due to concerns of structural teratogenicity as well as neurocognitive dysfunction with valproate and lower tolerability with carbamazepine. Although of importance in some regions, the prescribing of valproate has reportedly increased for non-epilepsy indications (9).

The aim of this study was to determine the extent of change in prescribing practice within the UK and Ireland Epilepsy and Pregnancy Register (UKIEPR). We also sought to determine if these changes impacted on the foetal MCM rate in this population. This has not been well studied to date. 


\section{Methods}

The UKIEPR is a prospective, observational, registration and follow up study that was set up in 1996 to determine the relative safety of AEDs taken in pregnancy. Methodological details have been published previously (2). Herein we report the congenital malformation outcomes of all pregnancies reported to the UKIEPR from 1996 through to August 2016.

Eligible cases were women with epilepsy taking any AED who were referred to the UKIEPR before the outcome of the pregnancy was known. Cases are referred by neurologists, epilepsy specialist nurses, obstetricians, midwives and by self-registering patients. Cases that are referred after an antenatal diagnosis of a probable or definite MCM are excluded. The main outcome measure is MCM rate defined as an abnormality of an essential embryonic structure requiring significant treatment, being present at birth or discovered in the first six weeks of life. Pregnancy losses where the outcome could not be determined were excluded, if a pregnancy loss occurred but a MCM was identified, these cases were included in the analysis. Outcome data are collected 3 months post-delivery by a questionnaire sent to the patient's general practitioner.

\section{Statistical Analysis}

Analyses of changing AED prescription trends over time have been carried out over the time course of the study from December 1996 through to 31 ${ }^{\text {st }}$ August 2016. Data from 1996 until December 2000 due to limitations in the data retrieval system is presented as cumulative data, contained in the data for the year 2000. For the rest of the time course of the study the data were recorded for individual years. The main analysis of the MCM rate data was by Poisson regression. The incidence risk ratio (IRR) is the measure most suitable for displaying these trends. A value of 1.000 represents no change in MCM risk from one year to the next. A value of 1.010 represents a $1 \%$ increase in year on year risk and 0.990 a $1 \%$ decrease. Trends in individual monotherapy and overall polytherapy prescribing were derived from data expressed as a percentage of all patients prescribed an AED, who were analysed by simple regression analysis.

Exact binomial $95 \%$ confidence intervals for proportions were calculated. SPSS Version.23.0 (IBM Corp., Armonk, NY) was used for the simple linear regression and Poisson regression analyses. Statistical significance level was set with a Bonferroni correction for 15 analyses at $\mathrm{P}<0.003(=0.05 / 15)$. 


\section{$\underline{\text { Results }}$}

Between December 1996 and 31st August 2016, complete outcome data were available for 9247 pregnancies, of which 6785 (73.4\%) were on monotherapy, $1858(20.1 \%)$ were on polytherapy regimens and 604 (6.5\%) were not on AEDs. Of the 8643 exposed to AEDs, 8181 pregnancies resulted in a live birth, of which 305 resulted in an infant with a MCM. Among those exposed to AED therapy, where the pregnancy resulted in foetal loss, there were 40 MCMs. Further details can be found in Supplementary table 1.

Of all cases treated with AEDs, the mean number who annually were treated with polytherapy is $17.5 \%$ (range $9-29 \%$ ). Simple regression carried out on the polytherapy annual trend, did not identify any significant overall change in the polytherapy prescribing rate (regression slope -0.14 , SE $0.22, \mathrm{P}=0.53$ ).

Figure 1 demonstrates the observed trends in prescribing changes, which clearly show the significant increase in the prescribing of lamotrigine and levetiracetam and the significant reduction in prescribing of valproate and carbamazepine. Based on a simple regression analysis the trend for valproate (regression slope -1.37, SE 1.00), [indicating that there has been a reduction of valproate registrations by $1.37 \%$ per year during the period of the study] carbamazepine (regression slope -1.19, SE 0.10) lamotrigine (regression slope 1.15, SE 0.22), and levetiracetam (regression slope 1.71, SE 0.11 ) all showed statistically significant changes over the time course of the study $(P<0.003)$. The miscellaneous group had a regression slope of -0.15 , SE $0.05(P=0.007)$ which was not significant after adjustment for multiple comparisons. The linear plots of these trends are presented in Figure 2 (See supplementary file 2). 


\begin{tabular}{|c|c|c|c|c|}
\hline \multirow[t]{2}{*}{ Treatment } & \multicolumn{4}{|c|}{ Incidence risk ratio 95\% Confidence intervals $\mathrm{P}$ Value } \\
\hline & (1) & Lower & Upper & \\
\hline Lamotrigine & 0.984 & 0.927 & 1.044 & 0.60 \\
\hline Carbamazepine & 1.057 & 0.999 & 1.117 & 0.06 \\
\hline Levetiracetam & 1.255 & 0.961 & 1.640 & 0.10 \\
\hline Sodium Valproate & 0.976 & 0.923 & 1.033 & 0.40 \\
\hline $\begin{array}{l}\text { Miscellaneous } \\
\text { monotherapy }\end{array}$ & 1.034 & 0.942 & 1.134 & 0.49 \\
\hline No AED group & 0.994 & 0.884 & 1.119 & 0.92 \\
\hline Polytherapy & 0.986 & 0.945 & 1.028 & 0.51 \\
\hline $\begin{array}{l}\text { Total (Monotherapy } \\
\text { and Polytherapy) }\end{array}$ & 0.979 & 0.956 & 1.002 & 0.08 \\
\hline
\end{tabular}

Table 1: Results from Poisson Regression analysis of annualised MCM rates.

Table 1 shows the results of a Poisson regression analysis carried out with MCM as the dependent variable, and year of study as a covariate. The analysis showed individual monotherapy drug MCM rates and the total MCM rate (monotherapy and polytherapy combined) did not change significantly over the course of the study. However the incidence risk ratio for total $\mathrm{MCM}$ rate does indicate a non-significant $2.1 \%$ reduction in the $\mathrm{MCM}$ rate per year. The trend for the MCM rate with lamotrigine, valproate, no AED group, polytherapy, levetiracetam, miscellaneous, and carbamazepine were all non-significant. 


\section{Discussion}

In this study we evaluated the AED reporting patterns to the UKIEPR and have demonstrated that there have been statistically significant changes in the preferred agents used in monotherapy prescribing to WWE in the UK and Ireland. The overall amount of polytherapy prescribed relative to monotherapy has not significantly changed, likely indicating that the severity of the cases referred to the UKIEPR over time has not changed. In keeping with other registry and population based prescribing studies $(5,6,7,8)$ our key finding is the significant change in the prescribing habits in monotherapy, favouring the less teratogenic drugs and those with a safer neurodevelopmental profile. The main factors which would explain these observed changes in prescribing practice, would include the reporting and dissemination of results from the various epilepsy and pregnancy registers, and in 2002 it was reported from retrospectively collected information that valproate exposure in utero resulted in reduced verbal Intelligence Quotient (10). In 2003 the Committee on Safety of Medicines (11) advised caution with valproate. More recently publications from the European Medicines Agency (EMA) (12), and the International League Against Epilepsy (ILAE) (13) have reiterating the importance of considering the safety of valproate use in women of childbearing age, with respect to risks of teratogenicity and neurodevelopmental abnormalities.

An alternative explanation for reduced numbers of valproate cases being registered is that patients and practitioners are better informed of the risks of valproate and consequently decline to register for the study, giving the impression of a reducing rate of valproate prescribing. However our findings are similar to a UK primary care prescribing database, suggesting that this is an accurate observation of reduced valproate prescribing (6). The reduction in the use of carbamazepine cannot be explained simply in terms of its teratogenicity but may be related to issues regarding poor tolerability due to its enzyme inducing effects $(2,3,4)$.

Despite only provisional data being available in a small number of prospectively followed children, detrimental cognitive effects have not been consistently found with levetiracetam and lamotrigine in children studied to the age of 6 (14). Despite these being provisional data, it is possibly a factor in women favouring these medication options.

If the increasing trends for MCM rate with levetiracetam and carbamazepine were subsequently found to be true, these would require explanation. Levetiracetam was introduced during the course of this study, and it took time to determine an accurate MCM rate, so giving the impression of an increasing MCM rate, albeit to its present low level. Regarding carbamazepine, the increasing MCM rate is perhaps of more interest. Patients 
taking carbamazepine at the start of this study differ phenotypically from those women registering now. At the outset of the register, carbamazepine was a first line treatment for focal epilepsy, now preference is given to lamotrigine or levetiracetam, thus women who are using carbamazepine now are potentially older, have more refractory epilepsy, and could potentially be on a higher dose of carbamazepine than women who first enrolled. This does require further work to determine what changes may be occurring over time in this population. The trend towards an increasing MCM rate within the miscellaneous group may reflect topiramate use which is known to be an intermediate risk monotherapy agent (15).

Although an overall reduction in MCM was observed during the study period, our Poisson regression analyses failed to detect it as statistically significant. Future work might allow for collaboration between the different pregnancy registries to reanalyse this question, as it is expected that data provided on a larger scale would show a statistically significant change in the MCM rate given the reduction in teratogenic drug use. The Australian Register of AEDs in Pregnancy (8) also found a downward trend in MCM rate with time but this failed to reach statistical significance. The authors attributed the trend to reduced use of valproate and a reduced dosage of valproate.

The strength of these data are the prospective nature of collection over a long time frame, resulting in the one of the largest cohorts of female epilepsy specific prescribing data reported to date. In terms of limitations of this present work, it is possible that prescribing trends are occurring within the population of WWE which are not reflected in this current work due to referral bias. In the initial stages the register received about 30\% referrals from the total eligible population of WWE, but this has reduced to $10-15 \%$ in recent years. The background rate of MCM may be falling due to other improvements in health, which could have resulted in a trend for reduced MCM. A further limitation is the fact that the dose of the AEDs was not analysed, and will be the subject of a future analysis. Data was analysed as annual aggregates and thus important co-variates in the assessment, such as smoking status, background change in MCM, folate status and history of malformation could not be included in the analysis. The particular prescribing changes occurring internally within the polytherapy group need to be re-evaluated in terms of dose and type of combinations used.

In conclusion, this study has shown a change in prescribing habit in the UKIEPR demonstrating a preference towards using AEDs with reduced potential for MCM and neurodevelopmental delay. Although being the largest epilepsy registry study to date to attempt to analyse the MCM rate over time, we have not found a statistically significant change. 


\section{Figure 1}

The annual changes in individual AED monotherapy and AED polytherapy registrations to the UK and Ireland epilepsy and pregnancy register.

Annual changes in individual monotherapy AED and polytherapy registrations

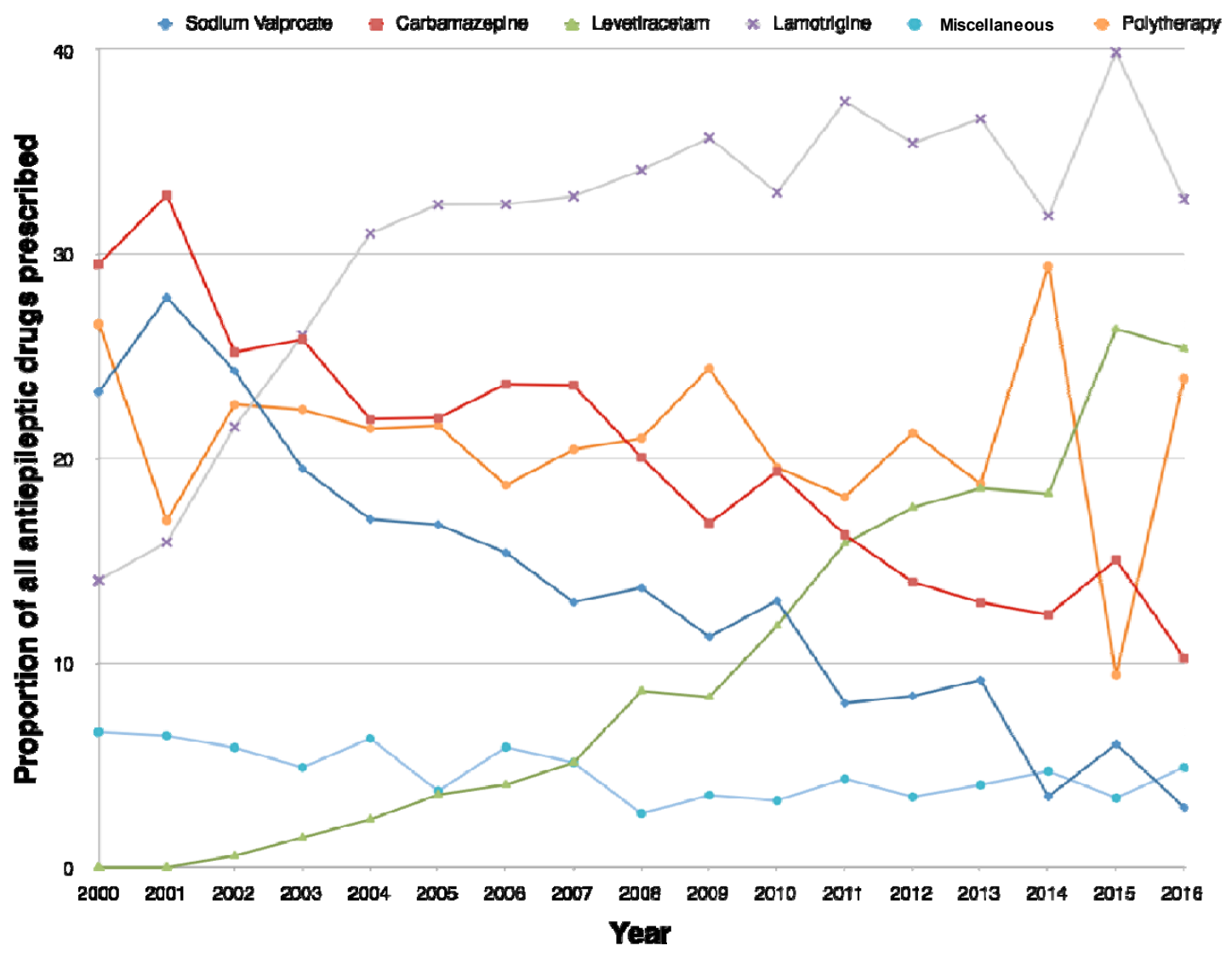




\section{Supplementary file 2}

Linear plots of individual AED monotherapy and AED polytherapy annual registrations.

(A) Percentage of patients on Sodium Valproate monotherapy of all AED treated patients

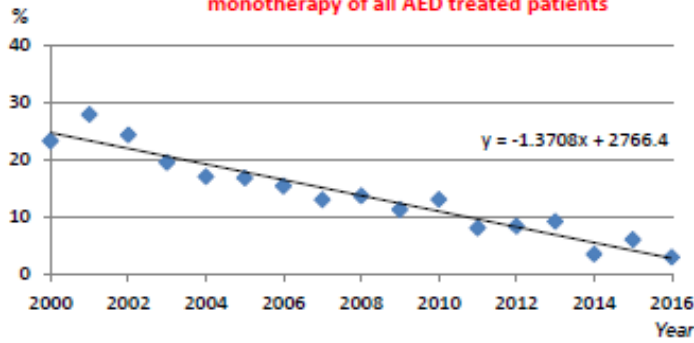

(C) Percentage of patients on Carbamazepine monotherapy of all AED treated patients

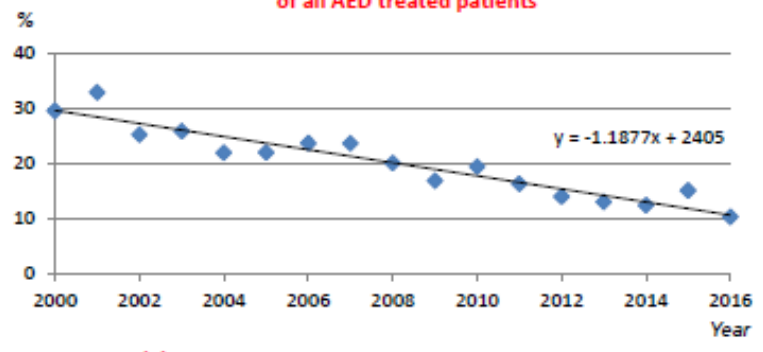

(E) Percentage of patients on Levetiracetam

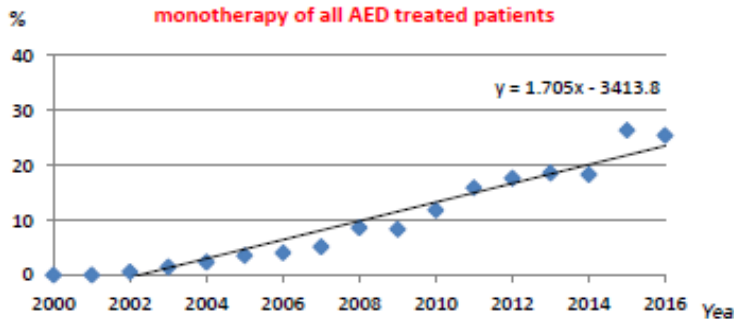

(B) Percentage of patients on Lamotrigine monotherapy of all AED treated patients

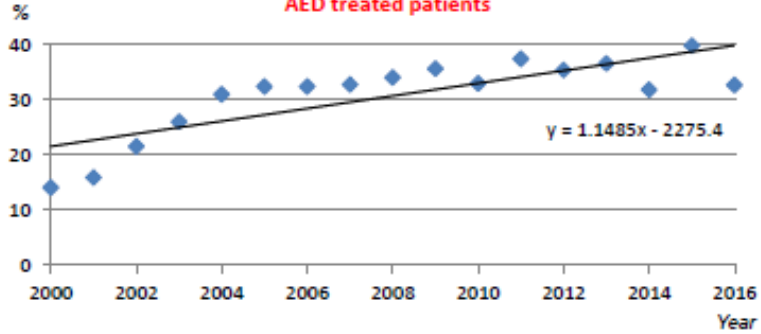

(D) Percentage of patients on Miscelleneous monotherapy AEDs of all AED treated patients

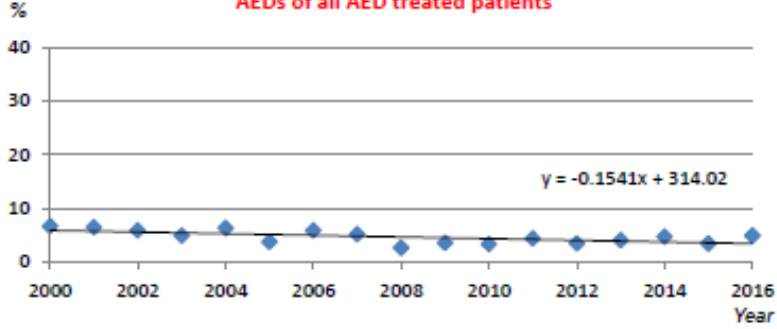

(F) Percentage of patients on Polytherapy AEDs of all AED treated patients

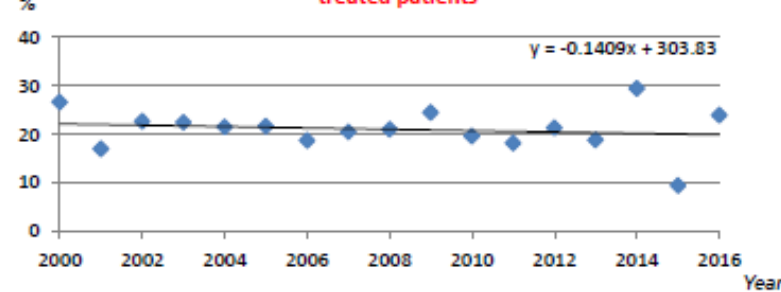




\section{$\underline{\text { References }}$}

(1) Kinney MO, Craig JJ. Pregnancy and Epilepsy: Meeting the challenges over the last 25 years. The rise of the pregnancy registries. Seizure 2017;44:162-168

(2) Campbell E, Kennedy F, Russell A, et al. Malformation risks of antiepileptic drug monotherapies in pregnancy: updated results from the UK and Ireland Epilepsy and Pregnancy Registers. J Neurol Neurosurg Psychiatry 2014;85:1029-34

(3) Hernández-Díaz S, Smith CR, Shen A, et al. North American AED Pregnancy Registry North American AED Pregnancy Registry. Comparative safety of antiepileptic drugs during pregnancy. Neurology 2012;78:1692-9

(4) Tomson T, Battino D, Bonizzoni E, et al. EURAP study group. Dose-dependent risk of malformations with antiepileptic drugs: an analysis of data from the EURAP epilepsy and pregnancy registry. Lancet Neurol 2011;10:609-17

(5) Xuerong W, Meador KJ, Hartzema A. Antiepileptic drug use by pregnant women enrolled in Florida Medicaid. Neurology 2015;84:944-950

(6) Man S-L, Petersen I, Thompson M, Nazareth I. Antiepileptic Drugs during Pregnancy in Primary Care: A UK Population Based Study. PLOS One 2012;7:e52339

(7) EURAP study group. Utilization of antiepileptic drugs during pregnancy: Comparative patterns in 38 countries based on data from the EURAP registry. Epilepsia 2009;50:23052309

(8) Vajda FJE, O'Brien TJ, Graham J, Lander CM, Eadie MJ. The Australian Register of Antiepileptic Drugs in Pregnancy: Changes over time in the epileptic population. Journal of Clinical neurosciences 2014;21;1478-1482

(9) Wen X, Meador KJ, Hartzema A. Antiepileptic drug use by pregnant women enrolled in Florida Medicaid. Neurology. 2015;3;84(9):944-50

(10) Adab N, Kini U, Vinten J et al. The longer term outcome of children born to mothers with epilepsy. Neurosurgery \& Psychiatry 2004;75:1575-1583.

(11) Sodium valproate and prescribing in pregnancy. Committee on Safety of Medicines. Current problems in pharmacovigilance. September 2003. Volume 29; page 6 Available at:http://webarchive.nationalarchives.gov.uk/20090705011742/http://www.mhra.gov.uk/Publi cations/Safetyguidance/CurrentProblemsinPharmacovigilance/CON007449). [Accessed online January 2018].

(12) European Medicines Agency. Assessment Report. Procedure Under Article 31 of Directive 2001/83/EC Resulting from Pharmacovigilance Data. 2014. Available at: http://www.ema.europa.eu/docs/en GB/document library/Referrals document/Valproate an d related substances 31/Recommendation provided by Pharmacovigilance Risk Assess ment Committee/WC500177352.pdf. [Accessed April, 2015]

(13) Tomson T, Marson A, Boon P, Canevini MP, Covanis A, Gaily E, Kälviäinen R, Trinka E. Valproate in the treatment of epilepsy in girls and women of childbearing potential. Epilepsia. 2015;56(7):1006-19

(14) Bromley R. The treatment of epilepsy in pregnancy: The neurodevelopmental risks associated with exposure to antiepileptic drugs. Reprod Toxicol 2016;64:203-10

(15) Hunt S, Russell A, Smithson W, et al. Topiramate in pregnancy: preliminary experiences from the UK Epilepsy and Pregnancy Register. Neurology 2008;71:272-276 